https://doi.org/10.48009/1_iis_2010_192-197

\title{
AN EVALUATION OF EMPLOYEES' ATTITUDES TOWARD SOCIAL NETWORKING IN THE WORKPLACE
}

\author{
Matthew A. North, Washington \& Jefferson College, mnorth@washjeff.edu
}

\begin{abstract}
The advent and rapid expansion of online social networking tools during the first decade of the $21^{\text {st }}$ century has enabled unprecedented levels of personal connection and communication which transcend time and distance limitations. At the same time, the addictive and open nature of these tools has exposed individuals to a host of negative consequences including identity theft, personal liability, and-of primary concern for employers - wasted time. This paper examines the attitudes of 59 American adults who are either currently in, or will soon enter, the professional workplace. Findings reveal that while there is consensus that use of social networking tools in the workplace is generally not appropriate, most continue to use such tools while at work. In addition, results of the study show that a significant number of participants see social networking as at least a marginal time waster and a potential liability — both major concerns for employers. Even while acknowledging this, most study participants affirmed a belief that some use while at work is justifiable.
\end{abstract}

Keywords: Social Networking, IS Ethics, Facebook, Twitter, LinkedIn, Workplace.

\section{INTRODUCTION}

A recent television advertisement for a new "Windows Phone" depicts man sitting in a workplace conference room, half listening to a presentation [20]. His Windows Phone is in his hand, clearly a ready distraction from the boredom of the business meeting. Of the people in the room, he is seated closest to the door. A personified Facebook icon creeps to the doorway and quietly gets his attention, and he motions for Facebook to quickly enter the room and hide beneath the table. As Facebook enters, the people around the table notice the disturbance and turn to look at the man, still holding his phone in his hand. Not wanting to be caught playing with Facebook in a business meeting, the man motions for a personified Microsoft Excel icon, also hiding beneath the table, to stand, giving his coworkers the impression that the man is actually working with a spreadsheet on his phone, something clearly relevant to his work and the current meeting.
The message: Get this phone because you'll be able to social network at work - just don't get caught!

This television commercial highlights an increasingly problematic issue in the workplace, particularly in countries and in jobs where Internet-enabled smart phones and Internet-connected workstations have become the norm. Job time lost to employee distractions has long been a concern for employers [5]. With the recent explosion of social networking tools including Facebook, Twitter, MySpace and others, coupled with the aforementioned increasing access to Internet-connected computers and mobile devices in the workplace, opportunities for technology-related employee distractions have never been higher $[6,11]$. Because of the rich nature of the media associated with social networking, concerns over harassment, intimidation, and even illegal activity become even greater for employers [2, 10, 12]. Evidence has shown that many employees are ignorant or uninformed about the potential risks they face themselves, or to which they expose their employers, by using social network sites at work. Further, as the current older generation of workers retires and is replaced by a younger, more technology savvy (and dependent) generation, the propensity to use these tools in the workplace is increasing $[1,16]$.

There are many who advocate for the use of social networking in the workplace. These tools, they argue, can become indispensable intra- and intercompany communication tools [9]. They can be exploited as powerful marketing vehicles [14]. Social networking can be used to improve businessto-consumer communication and relations [13], relax employees and keep them happy [7], and even help define the needed duties for newly created jobs [8].

As with virtually all technologies, the intersection of social networking and the workplace is a two-edged sword. This combination of pros and cons in the use of social networking creates a stormy ebb and flow of opinions about just how appropriate social networking tools are in the workplace.

\section{Statement of the Problem}


There is general consensus among American employers that the risks associated with the use of social networking in the workplace outweigh the benefits, and that they would therefore prefer that these tools not be used [3, 4, 15]. The lost productivity and even decreased quality of work performed because of social networking distractions are expensive $[2,18]$, and even employees agree that social networking isn't usually appropriate in the workplace $[4,6]$. Even still, employees continue to use social networking tools while on the clock, wasting time and subjecting both themselves and their employers to a host of potentially thorny issues $[10,12,17)$. This study seeks to identify the degree to which employees' attitudes will influence their decision to use social networking tools in the workplace, and whether or not those opinions match (or potentially will match) their actual workplace behavior when it comes to social networking at work.

\section{Literature Review}

In the 1980s, even before the advent of the Internet as it is conceived today, online service providers such as America Online, Prodigy and CompuServe were offering email, Usenet groups, and online public discussion boards [5]. Since then, the draw of social interaction online has tempted employees and drawn them away from their assigned work. As the Internet, and particularly the World Wide Web, became increasingly accessible in the early to mid-1990s, particularly in white-collar office buildings in developed nations worldwide, additional tools, web sites and services offered an expanding allure of options to distract employees from their work [1]. According to Frauenheim (2009), by the year 2008, the average American worker was spending between 21 and 26 percent of his or her paid time engaged in personal activities online [5].

As the 1980s provided genesis and the1990s formed the cradle for Internet-fueled workplace distractions, the first decade of the $21^{\text {st }}$ century has matured that environment [4]. The novelty of a web browser and an email box in the former decades gave way to rich multimedia content, multi-user collaboration, and full online application deployment in the latter decade. Simply put, the maturation of the Internet from the year 2000 to the present has made it more powerful, more tempting, and a lot more fun [3].

Without question, the Internet has both created new business opportunities and provided myriad new options for business tools that bridge both space and time [9, 13]. The Internet's impact on business has been no less significant than the creation of the assembly line or the inventions of the photocopier or fax machine [14]. Social networking sites and tools have the capacity to have such significant, or even greater, impacts than these technologies, but with significant risks to both productivity and quality [6, $10,14]$. While there are certainly opportunities for former technologies, such as the fax machine, to be misused or to serve as distractions, there has perhaps been no time in history when a new technology presented such a powerful attraction and potential risk as now [10].

Coupled with the risks and power of social networking comes a changing level of expectation, attitude and comfort with these technologies $[1,16]$. The generation of students now graduating from college has largely grown up with technologypersonal computers in their homes (if not in their own bedrooms), increasingly capable and affordable mobile phones, and of course, consistently faster and more broadly available connectivity to the Internet [16]. This has created a generation that has been characterized as "spoiled, impatient and entitled", all terms that can spell trouble for productivity and quality in the workplace. This generation of workers is keenly conditioned to expect ready Internet access and the freedom to engage in social networking at their leisure - and to be enabled and allowed to do so frequently. There is a real sense that this is a right, and that enjoyment at work, even if unrelated to job requirements, is a part of modern work life [2, 16]. In fact, a 2008 study by Telindus, a worldwide, European-based information technology services provider, showed that "...39 percent of 18-to-24year-olds would consider leaving their jobs if a Facebook ban were imposed..." [16].

The problem of entitlement in this context is exacerbated by businesses that write vague acceptable use policies, fail to disseminate or enforce the policies they have, or simply don't write such policies at all [17, 19]. While some $64 \%$ of American businesses are estimated to lack adequate, up-to-date acceptable use policies and controls, $80 \%$ of those that do have such measures are currently seen as failing to enforce them [17]. This sends a double message to workers that even if their employer implicitly prohibits use of social networking while working, they tacitly allow it [4]. In order to be effective, use policies must be comprehensive and current, articulated to employees, and then enforced [15]. Such policies must also extend to all tools that are available to employees during their workday, whether owned by the employee (e.g. cell phones) or the employer (e.g. an Internet-connected workstation). Without such 
controls, the expectations for technology use in the workplace environment become ambiguous [1].

This in turn feeds into a culture of rationalization. Employees who engage in social networking some number of times without corrective action will become more comfortable with their belief that this activity is appropriate for the workplace [18]. More difficult in terms of rationalization however is when social networking tools are used for some legitimate work-related activities. In such instances, it becomes much easier for employees to justify time spent on social networking sites, whether the majority of their time is spent doing work-related social networking or not [12]. For example, an employee might be asked to log into a company's Facebook page and post an announcement about an upcoming sale or promotion, a task that might require 15 minutes or so, but then spend an hour or more looking at pictures, posts or other content of friends on Facebook. Thus the legitimate marketing use of the social networking site becomes a significant personal distraction for the employee.

Other key rationalizations for use of social networking while at work include beliefs that an employee can perform their work while online [1, 18], and that taking time to socialize online during the workday will keep them happier and thus more productive during the periods when they are focused on their work [7]. While in some instances both justifications may be demonstrated to be feasible, employers surveyed in multiple studies do not generally accept such arguments $[11,15]$.

Ultimately, published research in this area has shown several consistent themes. First, the rising generation of professionals, especially white-collar professionals, expects both time and access to network socially during their workday [12]. Additionally, employers tend to exacerbate the problem by failing to write, disseminate and enforce policy about use of such technologies while at work [4, 19]. And finally, significant risks, both recognized and unknown, are posed by both employees and employers choosing to avoid addressing head-on the issue of personal social networking while at work $[10,17]$.

\section{METHODOLOGY}

In order to identify and compare current attitudes and behaviors of employees and prospective employees toward the use of social networking in the workplace, a brief survey was designed for this study. The survey was administered online, and electronic invitations (required in order to participate) were emailed to 126 graduate and undergraduate students at multiple institutions of higher education in the United States. These institutions cover all four continental time zones, and both the undergraduate and graduate populations include both full-time student/part-time worker and part-time student/fulltime worker profiles. Perhaps not surprisingly, the undergraduate group was predominantly comprised of the former profile, while the graduate group was primarily the latter. All students were either enrolled in a Bachelor of Information Systems \& Technology or Master of Information Systems \& Technology program at the time of their invitation.

The survey took less than ten minutes to complete, and no incentive for participation (other than a reassurance of complete anonymity) was offered. Questions posed to the participants included the following themes: use of social networking, preferred site(s), discontinuation of use, frequency of use, type of use, general attitude toward use, workplace attitude toward use, actual workplace use, greatest concerns with use, and demographic information.

Responses were collected between December of 2009 and March of 2010. Data were then aggregated and analyzed in order to report trends and statistical correlation.

\section{RESULTS}

The online survey was left open for a period of approximately four months, and an invitation to participate was sent to each prospective participant only once. An initial round of invitations was sent to 54 individuals in early December of 2009, and a second round was sent to the other 72 individuals in February of 2010. Of the 126 people invited, 59, or roughly $48 \%$ responded. While this response rate was lower than expected or hoped for, the researchers did not want to risk tainting the data by prodding others to participate if they were not interested or comfortable in doing so.

Of the 59 respondents, $31 \%$ were women $(69 \%$ undergraduate) and $69 \%$ were men $(68 \%$ undergraduate). These percentages roughly mirror to composition of the gender makeup of the student groups invited to participate, although it is noteworthy that the female participation rate was higher than the male participation rate, though not significantly.

Only five of the 59 respondents $(8 \%)$ claimed to not use social networking sites in any form, and all of 
these were in the age groups above 40 years old. Given the research cited previously in the literature review [e.g. 10, 16], this finding is not surprising. Of the other 54 who do use social networking (keeping in mind that respondents were asked to indicate all sites they use), 88\% indicated Facebook, 17\% indicated MySpace, and 12\% indicated LinkedIn. Surprisingly, only one respondent indicated they use Twitter, with a different participant offering this interesting comment regarding Twitter in the comment space of the survey: "Twitter has become a toxic forum for celebrities and athletes to make ***** [profane, read: 'idiots'] of themselves. Anyone who really understands what Twitter is stays away from it." Beyond the most commonly used, the most popular sites (asked as "Which site is your favorite?"), Facebook (85\%) was the clear favorite, followed by LinkedIn (10\%), then MySpace ( 5\%), and then all others combined $(\sim<1 \%)$.

Next, frequency of use was examined, which can serve as an indication of the probability a person will use social networking while in their workplace. Forty-six percent, including $100 \%$ of respondents under age 30, reported checking their social networking sites several times per day, while $24 \%$ check it once per day and $15 \%$ said they only check on their social networking sites randomly or sporadically.

When asked to indicate all of the reasons why they had ever quit a social networking site (or sites), $40 \%$ (21 respondents) stated that they simply didn't use it enough, 34\% said they liked another better, and $32 \%$ said they have never started using a site and then later quit using it. Only $17 \%$ ( 9 people) said they had quit over privacy concerns, $15 \%$ admitted to quitting because they were wasting too much time, and only $4 \%$ said they quit because their own, or their friends', behavior embarrassed them or posed a potential problem for them. One person stated in free form comments: "I'm trying to get a job and I can't afford to have something on Facebook cost me an interview." No other comments in this spirit were received, raising questions about whether or not the respondents are even thinking about such professional ramifications of social networking use.

Participants were asked their opinion of the biggest problem with the use of social networking in general. Forty-seven percent (27 of 59) indicated that they can become addictive and waste time as the biggest problem. This is interesting because very few participants reported quitting social networking for this reason. One may assume that if users report being concerned over wasting time, they may choose to discontinue the practice they perceive to be a time drain, however a Pearson test between these two metrics shows no correlation $(p=.29)$. Even as the participants acknowledge social networking sites as potential time wasters, their behavior shows that they do not take steps to stop wasting time by not using them. Further, 36\% of participants acknowledge privacy concerns as the biggest problem with social networking, but only $17 \%$ had quit for this reason. A Pearson test again reveals no statistical relationship between belief and behavior $(p=-.30)$.

If this then is the reality of today's employee and prospective employee behavior, what then is the likelihood that social networking sites are being used, and abused, within the workplace? An overwhelming $81 \%$ of survey respondents admit to either using, or planning to use, social networking sites while on the clock. Only 3\% (two people) stated that using social networking sites on company time would be unethical. Not surprisingly, both of these individuals are among the five who reported not using social networking sites at all. Of the $81 \%$ who claim to use social networking tools while on the job, all admit that their use has been primarily personal and not job-related, and only $13 \%$ state that they have ever used social networking while on the job to perform assigned work duties. Fewer than $70 \%$ knew if their employer currently has a policy regarding use of social networking tools while on the job. Comments from participants along these lines support these data: "Where I work, I think there is a policy, but most people don't know about it, no one follows it, and as long as you get your work done, nobody cares." Such comments would certainly coincide with Thomson's findings [17].

Survey respondents were asked specifically about the appropriateness of using social networking sites at work. Sixty-four percent (38 people) agreed with the statement: "They are good for communication with family or friends, but are not appropriate for business use." Only 22\% (13 people) claimed they are appropriate for both business and personal use in the workplace." When asked if social networking tools might be useful and therefore appropriate for a specific business-related purpose, $41 \%$ agreed that they could be, $22 \%$ didn't feel they would make a difference one way or another, and $15 \%$ said they would still serve as a distraction. In the area of attitude toward appropriateness of use in the workplace, again no correlations were found. When comparing the level of admitted workplace use to the level of belief that use is not appropriate, no meaningful negative correlation, which would be expected, was found $(p=-.23)$. The interpretation 
here is that although workers generally do believe that they should not be using social networking while they're at work, they don't seem to care that much, and are doing it anyway. Observations from previously cited research would dovetail with this finding. Employees continue to use social networking in the workplace even if they know they shouldn't [1, 4], they do not necessarily concern themselves if their use is a violation of policy [5, 18], and there is little worry that they may at some point suffer negative consequences as a result of their use $[17,19]$.

\section{Future Study}

The evidence found and presented in this study demonstrates that social networking is in fact an activity taking place extensively in the modern workplace, and that most of that social networking is not work related. This subsequently begs the question: What is to be done? Literature has been cited that suggests that many businesses are currently turning a blind eye to issue, thereby exacerbating the problem as they condition employees, perhaps unwittingly, to believe that the practice is acceptable. Future study in this area may include surveying policy makers and managers to determine their attitudes toward workplace social networking. Do policy makers and manager care enough to intervene and to step up their efforts to curb the activity?

Additional topics of interest might include a closer look at the amount of time employees are spending specifically on non-work related social networking, and correlating such numbers with a productivity metric. Some employees' claim that social networking while at work makes them happier and more productive [7], and putting this claim to the test would be an interesting proof. Further, a review of consequences suffered by businesses or employees could be an interesting area for examination.

\section{CONCLUSIONS}

It is clear that social networking is occurring in the workplace and that generally employees believe that it is not necessarily an appropriate practice, but they do it anyway. Without greater degrees of enforcement from employers, and with a rising generation of employees conditioned to frequently engage in social networking, the issue is likely to expand further. Employers who wish to curb the behavior must begin immediately to form and disseminate policies regarding social networking while on the clock, or be perceived as condoning it.

\section{REFERENCES}

1. Arnold, J. T. (2009). Twittering and Facebooking While They Work. HR Magazine, 54(12), 53-55.

2. Blades, T. (2010). Does Your Firm Ban Facebook and Twitter? Law Office Management \& Administration Report, 10(2), 5-6.

3. Breslin, T. (2009). When Social Networking Enters the Workplace. Massachusetts Nurse, 80(8), 14.

4. Devitt, Tamara I. (2009). Social Networking and the Workplace? Orange County Business Journal, 32(37), 23.

5. Frauenheim, E. (2009). Social Media, e-Mail Remain Challenging for Employers. Workforce Management, 88(13), 4.

6. Holmes, A. (2010). Anti-Social. Government Executive, 42(2), 7-9.

7. Kesten, R. (2009). Weighing in on the Workplace: Stress and productivity. Fairfield County Business Journal, 48(42), 22.

8. Kilduff, M. \& Brass, D. J. (2010). Job Design: A social network perspective. Journal of Organizational Behavior, 31(2/3), 309-318.

9. Kleinschmidt, J. (2009). Cross-Company Knowledge Sharing. Information Management, 19(7), 56.

10. Maltby, K. V. \& Pilch, C. (2009). Fraternization, Romance, and Liability. Business West, 26(16), 36-58.

11. Markel, G. (2009). How Learning Professionals can Keep Technology Distractions at Bay. Technology \& Development, 63(9), 68-69.

12. Maryott, M. L. (2010). Employer Perils in the Social Networking Age. Orange County Business Journal, 33(3), 6.

13. Matsuda, C. (2010). Yes, I Blog at the Office. Entrepreneur, 38(3), 72-74.

14. Mellon-Hogan, L. (2009). Twitter is the Latest Electronic Tool with Workplace Pros and Cons. HR Focus, 86(8), 8-9.

15. Schiller, K. (2009). Employers Crack Down on Social Networking. Information Today, 26(10), 21.

16. Sujansky, J. G. (2009). Spoiled, Impatient, \& Entitled: Why you need strong millennials in your workplace. Business Journal, 23(36), 1114.

17. Thomson, R. (2009, Oct. 6). Firms Bury Their Heads Over Social Networking. Computer Weekly, 8.

18. Whadcock, I. (2010). Yammering Away at the Office. Economist, 394(8667), 14-17, 3. 
19. Wright, A. D. (2010). Employers, Employees Shun Policies On Social Networking. $H R$ Magazine, 55(2), 18-20.

20. YouTube. "Meetings are More Fun with Windows Phone." [Electronic Version].

Retrieved 18 March 2010 from: http://www.youtube.com/v/1KWnjs0Z32A\&hl. 